\title{
Experimental Study on Manufactured Sand-Soil Bearing Capacity W-T-BC Model Based on Mechanical Response of Rotary Penetration
}

\author{
Xiangfeng Lv iD, ${ }^{1,2}$ Shuo Zhang, ${ }^{3}$ and Hongyuan Zhou ${ }^{3}$ \\ ${ }^{1}$ School of Civil and Resource Engineering, University of Science \& Technology Beijing, Beijing 100083, China \\ ${ }^{2}$ Beijing Key Laboratory of Urban Underground Space Engineering, University of Science \& Technology Beijing, \\ Beijing 100083, China \\ ${ }^{3}$ Geotechnical Engineering Research Center, Beijing Municipal Engineering Research Institute, Beijing 100037, China \\ Correspondence should be addressed to Xiangfeng Lv; beijinglxf2013@163.com
}

Received 5 July 2019; Accepted 3 December 2019; Published 21 December 2019

Academic Editor: Antonio Riveiro

Copyright (C) 2019 Xiangfeng Lv et al. This is an open access article distributed under the Creative Commons Attribution License, which permits unrestricted use, distribution, and reproduction in any medium, provided the original work is properly cited.

Studies are lacking in establishing the quantitative relationship between the mechanical response and the rock and soil mechanical parameters by digital rotary penetration. In this study, based on the custom-built rock and soil strength parameter test device and the three-dimensional flexible boundary loading device, we conducted an experimental study of the manufactured sand-soil model with moisture contents of $5 \%, 10 \%$, and $15 \%$ under different confining pressures $(0,0.12,0.18$, 0.24 , and $0.42 \mathrm{MPa}$ ). Analysis was conducted on the influencing factors and laws of water content on the experimental results, and a quantitative relationship model (W-T-BC model) between the drilling torque and the bearing capacity of manufactured sand-soil under the condition of different water contents was established. Through failure detection verification on the manufactured sand-soil-filled subgrade of the Taihang Mountains Expressway in Beijing, the average conformity between the calculated value of the bearing capacity of the W-T-BC model and the standard experimental bearing capacity was $93.23 \%$, which proved the validity and accuracy of the model. Finally, the rigid-soft interface grid body of sand-soil particles was analyzed. The reason why the manufactured sand-soil exhibited better stability than homogeneous soil under the action of external force in microcosmic aspect was expounded. The establishment of the W-T-BC model provided a scientific basis and important reference for further study of the relationship between mechanical response and force parameters under different conditions of different materials.

\section{Introduction}

The digital rotary penetration technology allows people to monitor, acquire, and control real-time footage rate, rotary speed, torque, propulsion, and other drilling parameters during drilling process [1-3]. The characterization of the strength parameters of underground rock and soil by drilling parameters has gradually become a popular research topic in the field of geotechnical engineering. The establishment of a comprehensive and targeted quantitative model for the relationship between the response parameters of rotary penetration and the mechanical parameters of rock and soil has become a difficult problem to solve in this field.
Previous studies have shown that a large amount of geological information about the stratum can be represented by the mechanical response during the drilling process $[4,5]$. Scholars have conducted a significant amount of research on the quantitative model to characterize rock strength with response parameters of rotary penetration. Signorelli and Wang [6] used the drilling rate derived from the specific energy concept to determine the grade of rock-soil and weathered rock mass. Tian et al. [7] analyzed the variation characteristics of the working parameters of the drilling rig from the perspective of drilling energy and used the drilling parameters to generate the drilling energy variation curve and the drilling specific energy variation curve. Thus, they 
identified the interface and studied the surrounding rock layers of tuff formations. Gao [8], Pfister [9], Cao et al. [10], and Dahl et al. [11] applied mechanical response monitoring techniques based on rotary penetration to actual engineering measurements using torque, rotating speed, footage, and other parameters to identify the rock and soil properties. Schunnesson [12] established a rock quality designation (RQD) estimation method based on the drilling parameters. Karasawa et al. [13] used three types of milling teeth with a diameter of $98.43 \mathrm{~mm}$ and a $101.6 \mathrm{~mm}$ diameter drill cutter on the indoor drilling rig on four rock samples with a compressive strength ranging from 4 to $118 \mathrm{MPa}$. The drilling and cutting tests were carried out, and the drill pressure, torque, rotational speed, drill bit displacement, and time were measured. Yue [14] conducted drilling experiments on weathered granite in Hong Kong and evaluated the formation of weathered granite according to the parameters while drilling. Chen and Yue [15] introduced a drilling process monitoring (DPM) system based on drill hole data analysis to locate the weak areas of weathered rock mass. Tan et al. [16] established a formula for the drillability index based on the coupling relationship among effective axial pressure, rotational speed, perforation rate, and drillability index. Tan et al. also analyzed the sensitivity of the new drillability index in stratigraphic identification and expounded its physical meaning as it relates to stratigraphic identification. Song et al. $[17,18]$ studied the mechanism of rotary penetration. In order to realize in situ rotary penetration in the soft rock, they used blocks, super gypsum, and mold gypsum samples to simulate soft rock with a uniaxial compressive strength of less than $15 \mathrm{MPa}$. They completed many experiments to study the variation law among axial pressure, torque, compressive strength, and shear strength of soft rocks and obtained the relationship between drilling parameters and sample strength. Based on the ability analysis method. Wang et al. [19] established the quantitative relationship model (DP-UCS model) between the drilling parameters and the uniaxial compressive strength of the rock through theoretical derivation and digital drilling experiments on entire rocks. Lv et al. [20] proposed a new method about evaluating the bearing capacity of soils using drilling parameters. Digital rotary cone penetration technology is also widely applied to stratigraphic division, gradation of rock surrounding tunnels, and weak rock/soil deformation monitoring [21-23]. However, model studies are unclear about the relationship between the mechanical response and the force parameters of engineering materials created by digital rotary penetration, such as soil. In particular, there are few research reports on the digital rotary penetration of new manufactured sand-soil engineering materials.

A customized strength parameter testing device for manufactured sand-soil was developed for this study to conduct the three-dimensional flexible boundary loading experiment and the rotary penetration test under three water content levels and five confining pressure levels. Analysis was conducted on the influencing factors and laws of water content on the experimental results, and the W-T$\mathrm{BC}$ relationship model between torque of the manufactured sand-soil drilling response parameters and bearing capacity was established. Through failure detection verification on the manufactured sand-soil-filled subgrade of the Taihang Mountain Expressway, the average conformity between the calculated value of the bearing capacity of the W-T-BC model and the standard experimental bearing capacity was $93.23 \%$, which proved the validity and accuracy of the model.

\section{Equipment and Research Method of the Experimental Relationship Model}

2.1. Experimental Equipment. The manufactured sand-soil torque was tested with the custom-built rotary penetration device for testing rock-soil strength parameters, in which the data acquisition system collected the torque value $(0 \sim 200 \mathrm{~N} \cdot \mathrm{m})$, the $12 \mathrm{~mm}$ diameter photoelectric encoder collected the drilling depth, and the computer and system software generated the relationship between drilling depth and three other parameters (torque, propulsion, and rotation speed) in real time. The rotary penetration system provided a maximum propulsion of $7.5 \mathrm{kN}$ with a maximum speed of $800 \mathrm{r} \cdot \mathrm{min}^{-1}$ and a maximum drilling depth of $15 \mathrm{~m}$.

The three-dimensional flexible boundary loading device included a homogeneous multiline hydraulic pump station, a hydraulic jack, and a reinforced rigid plate, which can provide a maximum confining pressure of 1.2 MPa. The maximum stroke of the hydraulic jack was $50 \mathrm{~mm}$. The maximum relative displacement between the loading plates was $50 \mathrm{~mm}$, and the cube model size was $100 \times 100 \times 100 \mathrm{~cm}$. The important components of the device and the overall schematic of the device are shown in Figure 1.

2.2. Research Theoretical Support and Method. The existence of strong mathematical correlation between the mechanical response and the mechanical parameters of rock and soil mass had been proved by many scholars through a large number of experiments [24-27]. Lv et al. [20] conducted the theoretical analysis of the rotary penetration ground breaking process and pointed that with fixed drill bit geometric parameters, footage rate, and rotational speed the relationship between the mechanical responses from the rotary cone penetration (torque and propulsion) and formation bearing capacity is linear, which can be simplified as

$$
[P]=K^{\prime} T,
$$

where $[P]$ is the allowable bearing capacity of the formation, $T$ is the torque, and $K^{\prime}$ is the coefficient to be determined. In this experiment, the above theory is used as support and manufactured sand-soil as experimental material to study the mathematical relationship between bearing capacity and torque of foundation.

Manufactured sand-soil models with a volume of $1 \mathrm{~m}^{3}$ and moisture content levels of $5 \%, 10 \%$, and $15 \%$ were created. Table 1 lists the physical parameters of the 


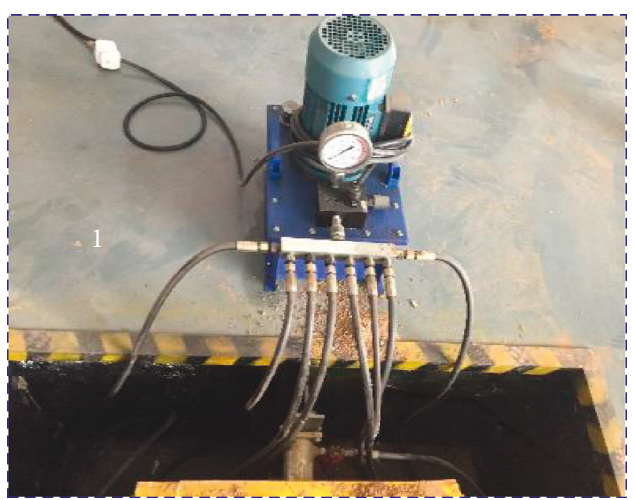

(a)

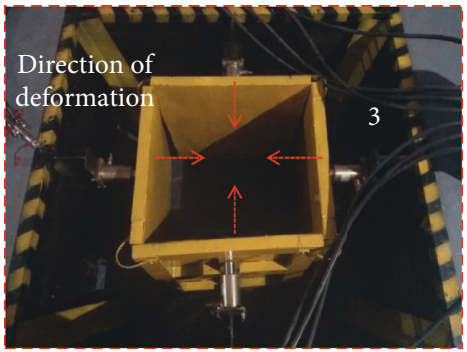

(c)

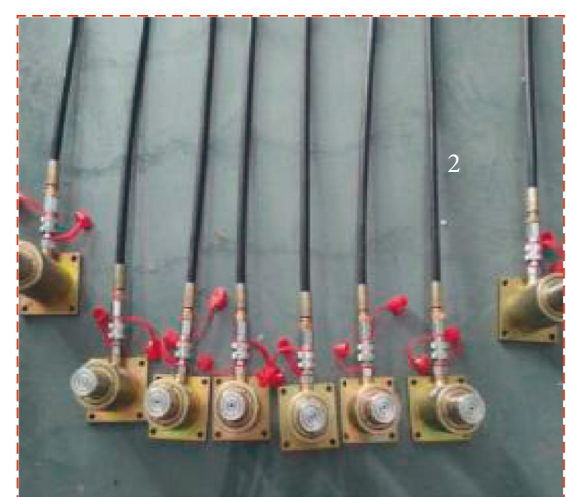

(b)

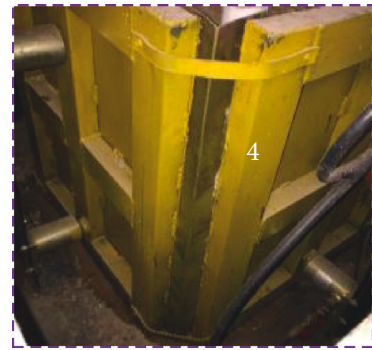

(d)

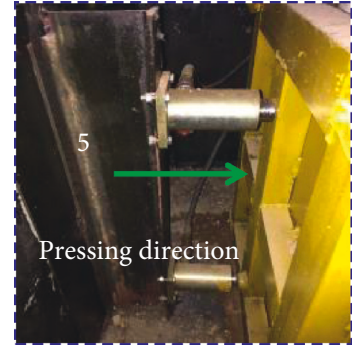

(e)

FIgURE 1: Three-dimensional flexible boundary loading device: (1) homologous multiline hydraulic pump station, (2) hydraulic tubing, (3) boundary steel plate, (4) loading plate and flexible joints, and (5) hydraulic jack.

TABLE 1: Description of variables in the present study.

\begin{tabular}{lcccccccc}
\hline Type & $\begin{array}{c}\text { Water } \\
\text { content } w(\%)\end{array}$ & $\begin{array}{c}\text { Dry density } \rho_{d} \\
\left(\mathrm{~g} \cdot \mathrm{cm}^{-3}\right)\end{array}$ & $\begin{array}{c}\text { Liquid limit } \\
W_{L}(\%)\end{array}$ & $\begin{array}{c}\text { Plastic limit } \\
W_{P}(\%)\end{array}$ & $e$ & $G_{s}$ & $\begin{array}{c}\text { Weight of the } \\
\text { samples } m_{s}(\mathrm{~kg})\end{array}$ & $\begin{array}{c}\text { Weight of the water } \\
m_{w}(\mathrm{~kg})\end{array}$ \\
\hline $\begin{array}{l}\text { Mechanism } \\
\text { sand-soil I }\end{array}$ & 5 & 1.57 & 25.7 & 14.9 & 0.74 & 2.71 & 1570 & 78.50 \\
$\begin{array}{l}\text { Mechanism } \\
\text { sand-soil II }\end{array}$ & 10 & 1.57 & 25.9 & 13.5 & 0.70 & 2.72 & 1570 & 157.00 \\
$\begin{array}{l}\text { Mechanism } \\
\text { sand-soil III }\end{array}$ & 15 & 1.57 & 23.1 & 17.6 & 0.71 & 2.71 & 1570 & 235.50 \\
\hline
\end{tabular}

manufactured sand-soil model with different water content levels. All physical properties were determined according to the ASTM [28] standard method. A total of 60 sets of rotary penetration tests were conducted for the manufactured sandsoil models with three different water content levels under different confining pressures of $0,0.12,0.18,0.24$, and $0.42 \mathrm{MPa}$. Under the same confining pressure, four sets of drilling experiments with a drilling depth of $60 \mathrm{~cm}$ were performed and data were recorded for each manufactured sand-soil model. In the test, a thin-walled diamond drill with a diameter of $4 \mathrm{~cm}$ was used, the rotation speed was fixed at $500 \mathrm{r} \cdot \mathrm{min}^{-1}$, the footage rate was $15 \mathrm{~cm} / \mathrm{min}$, and the propulsive force was $10 \mathrm{kN}$.

A total of 60 sets of light-powered penetration tests were carried out and four penetration tests were conducted under the conditions with the same water content and the same confining pressure. The depth of the penetration was $60 \mathrm{~cm}$. In the test, considering the stress diffusion, the drill hole was filled with a steel pipe having a diameter of $39.5 \mathrm{~mm}$, and the penetration point was less than $30 \mathrm{~cm}$ from the drill hole $[29,30]$.

\section{Study on the Manufactured Sand-Soil W-T-BC Relationship Model under the Influence of Water Content}

3.1. Manufactured Sand-Soil Bearing Capacity Variation Characteristics under the Influence of Water Content. The experiment provided 60 sets of light dynamic penetration test values and corresponding bearing capacity values. The results are shown in Tables $2-4$. Bearing capacity at the confining pressures of $0,0.12,0.18,0.24$, and $0.42 \mathrm{MPa}$ were $145,184.5,200,232$, and $288 \mathrm{kPa}$, respectively, for the manufactured sand-soil with a water content of $5 \%, 82.5$, $106,122.5,136.5$, and $177.5 \mathrm{kPa}$ for the manufactured sandsoil with a water content of $10 \%$; and $35,50.5,58.5,75$, and 
TABLE 2: Light dynamic penetration test results in manufactured sand-soil I.

\begin{tabular}{lccccccccc}
\hline & De(cm) & \multicolumn{2}{c}{$\begin{array}{c}\text { No. 1 measuring } \\
\text { point }\end{array}$} & \multicolumn{2}{c}{$\begin{array}{c}\text { No. 2 measuring } \\
\text { point }\end{array}$} & \multicolumn{2}{c}{$\begin{array}{c}\text { No. } 3 \text { measuring } \\
\text { point }\end{array}$} & $\begin{array}{c}\text { No. } 4 \text { measuring } \\
\text { point }\end{array}$ \\
& $\mathrm{CP}(\mathrm{MPa})$ & $0 \sim 30$ & $30 \sim 60$ & $0 \sim 30$ & $30 \sim 60$ & $0 \sim 30$ & $30 \sim 60$ & $0 \sim 30$ & $30 \sim 60$ \\
\hline & 0 & 145 & 145 & 121 & 168 & 137 & 152 & 130 & 152 \\
Bearing capacity $(\mathrm{kPa})$ & 0.12 & 168 & 184 & 176 & 184 & 161 & 176 & 184 & 161 \\
& 0.18 & 192 & 200 & 200 & 200 & 184 & 200 & 184 & 192 \\
& 0.24 & 215 & 240 & 223 & 231 & 231 & 215 & 223 & 240 \\
& 0.42 & 262 & 294 & 262 & 286 & 278 & 255 & 262 \\
\hline
\end{tabular}

Remark: $\mathrm{De}=$ Depth, $\mathrm{CP}=$ Confining Pressure .

TABLE 3: Light dynamic penetration test results in manufactured sand-soil II.

\begin{tabular}{lccccccccc}
\hline & De $(\mathrm{cm})$ & \multicolumn{2}{c}{$\begin{array}{c}\text { No. } 1 \text { measuring } \\
\text { point }\end{array}$} & \multicolumn{2}{c}{$\begin{array}{c}\text { No. 2 measuring } \\
\text { point }\end{array}$} & \multicolumn{2}{c}{$\begin{array}{c}\text { No. } 3 \text { measuring } \\
\text { point }\end{array}$} & $\begin{array}{c}\text { No. } 4 \text { measuring } \\
\text { point }\end{array}$ \\
& $\mathrm{CP}(\mathrm{MPa})$ & $0 \sim 30$ & $30 \sim 60$ & $0 \sim 30$ & $30 \sim 60$ & $0 \sim 30$ & $30 \sim 60$ & $0 \sim 30$ & $30 \sim 60$ \\
\hline & 0 & 76 & 82 & 76 & 97 & 103 & 83 & 75 \\
Bearing capacity $(\mathrm{kPa})$ & 0.12 & 105 & 106 & 105 & 105 & 104 & 105 & 105 & 107 \\
& 0.18 & 121 & 123 & 125 & 121 & 118 & 120 & 120 & 123 \\
& 0.24 & 129 & 137 & 130 & 137 & 129 & 145 & 133 \\
& 0.42 & 167 & 176 & 178 & 178 & 175 & 175 & 176 \\
\hline
\end{tabular}

Remark: $\mathrm{De}=$ Depth, $\mathrm{CP}=$ Confining Pressure

TABLE 4: Light dynamic penetration test results in manufactured sand-soil III.

\begin{tabular}{cccccccccc}
\hline & De $(\mathrm{cm})$ & \multicolumn{2}{c}{$\begin{array}{c}\text { No. } 1 \text { measuring } \\
\text { point }\end{array}$} & \multicolumn{2}{c}{$\begin{array}{c}\text { No. 2 measuring } \\
\text { point }\end{array}$} & \multicolumn{3}{c}{$\begin{array}{c}\text { No. } 3 \text { measuring } \\
\text { point }\end{array}$} & \multicolumn{2}{c}{$\begin{array}{c}\text { No. } 4 \text { measuring } \\
\text { point }\end{array}$} \\
& CP (MPa) & $0 \sim 30$ & $30 \sim 60$ & $0 \sim 30$ & $30 \sim 60$ & $0 \sim 30$ & $30 \sim 60$ & $0 \sim 30$ & $30 \sim 60$ \\
\hline & 0 & 36 & 37 & 38 & 35 & 36 & 42 & 35 & 36 \\
Bearing capacity $(\mathrm{kPa})$ & 0.12 & 48 & 52 & 52 & 48 & 46 & 54 & 50 & 46 \\
& 0.18 & 57 & 58 & 60 & 59 & 55 & 54 & 60 & 59 \\
& 0.24 & 78 & 72 & 70 & 86 & 76 & 76 & 75 & 82 \\
& 0.42 & 98 & 101 & 102 & 98 & 101 & 101 & 102 \\
\hline
\end{tabular}

Remark: $\mathrm{De}=$ Depth, $\mathrm{CP}=$ Confining Pressure

$98 \mathrm{kPa}$ for the manufactured sand-soil with a water content of $15 \%$.

3.2. Effect of Water Content on the Mechanical Response of Sand-Soil while Drilling. A total of 60 sets of torque values in rotary penetration were collected in the experiment. Four experiments under the same water content and confining pressure were labeled. One curve of experiment is selected from four experiment randomly to display, as shown in Figures 2-4(the number behind the pressure value is the experimental label). The average drilling torques under the confining pressures of $0,0.12$, $0.18,0.24$, and $0.42 \mathrm{MPa}$ are $24.09,27.87,31.38,34.86$, and $41.77 \mathrm{~N} \cdot \mathrm{m}$, respectively, for the manufactured sandsoil with a moisture content of $5 \%$ and 20.83, 22.56, $23.725,25.16$, and $29.48 \mathrm{~N} \cdot \mathrm{m}$ for the manufactured sandsoil with a moisture content of $10 \%$. The bearing capacities of the manufactured sand-soil with a moisture content of $15 \%$ are $9.755,12.825,14.50,16.145$, and $22.385 \mathrm{~N} \cdot \mathrm{m}$, respectively, at the confining pressures of 0 , $0.12,0.18,0.24$, and $0.42 \mathrm{MPa}$.

\section{W-T-BC Relationship Model for Mechanical Response and Bearing Capacity in Rotary Penetration}

The test results of the manufactured sand-soil with three different water content levels under different confining pressures are shown in Tables 5-7. Statistical analysis of the data shows that when the diameter of the drill bit is $4 \mathrm{~cm}$ and the drilling parameters (drilling speed, rotational speed, and propulsion) are determined, the linear equation of the manufactured sand-soil bearing capacity $(Q)$ and the bit torque $(N)$ is $Q=-47.92+7.99 \mathrm{~N}$ (Adj. $R$-square $=0.98, \mathrm{~N}$ : 20 50), $Q=-133.11+10.59 \mathrm{~N}$ (Adj. $R$-square=0.93, $\mathrm{N}$ : $15 \sim 30$ ), and $Q=-12.85+5.04 \mathrm{~N}$ (Adj. $R$-square $=0.98, \mathrm{~N}$ : 10 25) for manufactured sand-soil with moisture contents of $5 \%, 10 \%$, and $15 \%$, respectively. The fitting curve is shown in Figure 5.

It can be seen from Figure 5 that the linear relationship between the torque and the bearing capacity of the three fitting curves is significant; under the same water content, all the three curves show a linear increase, indicating that the torque and the bearing capacity are positively correlated. 


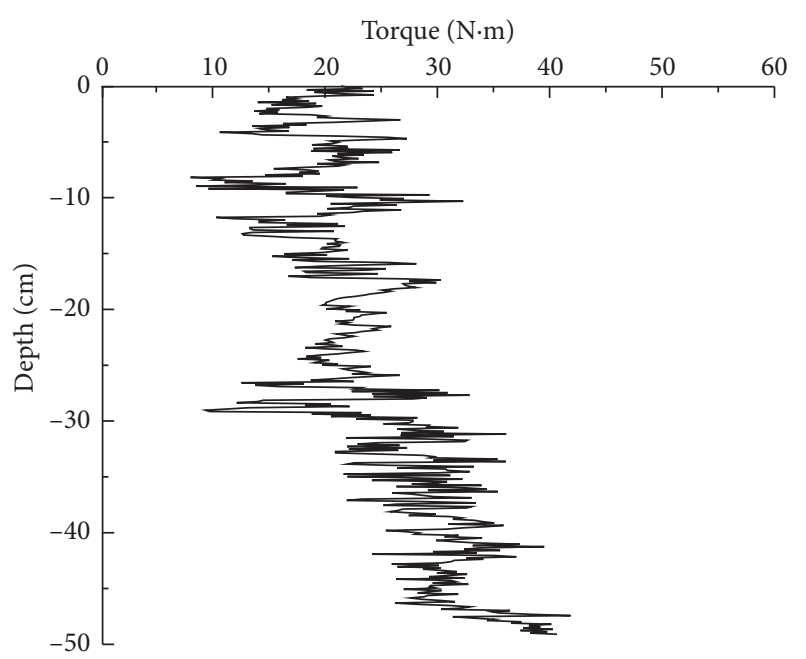

(a)

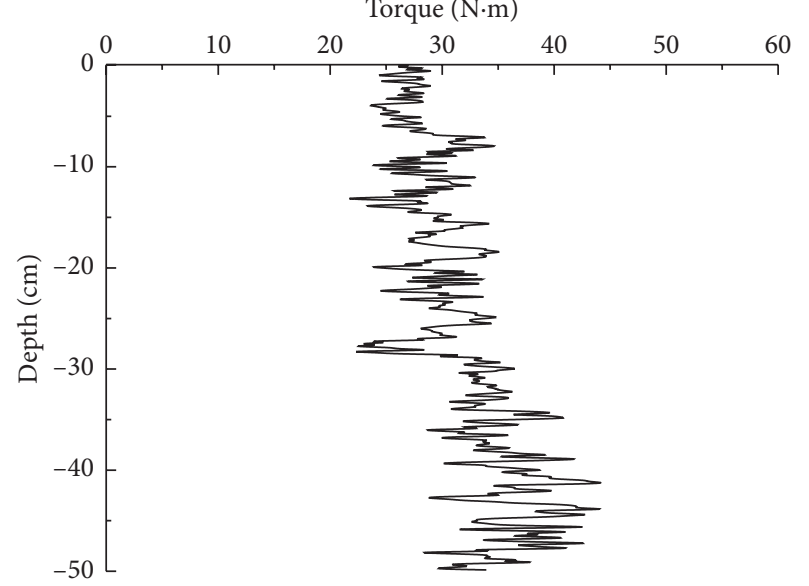

(c)

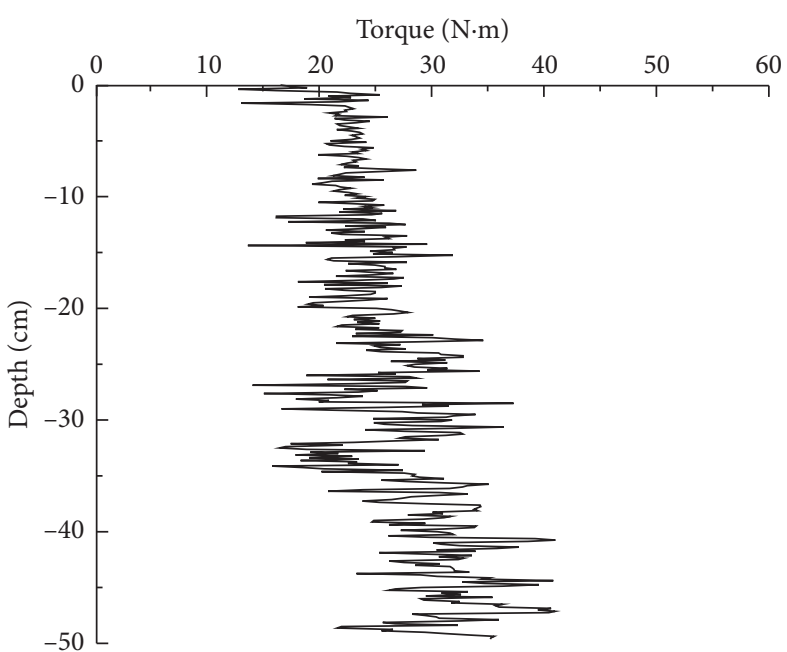

(b)

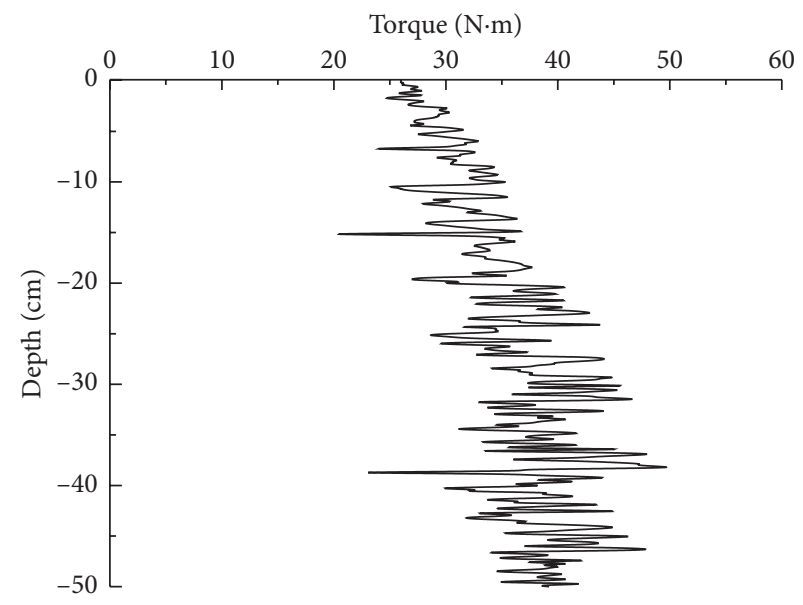

(d)

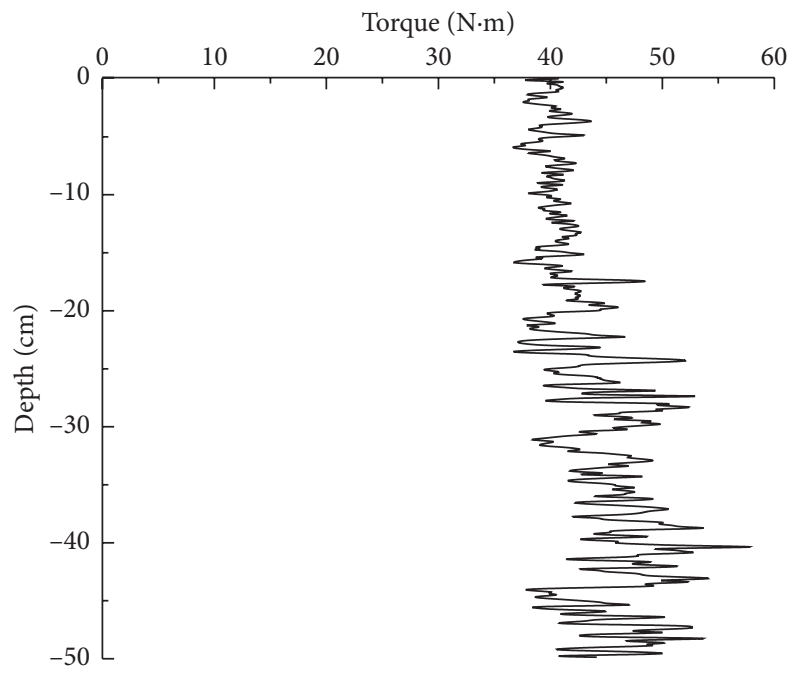

(e)

FIGURE 2: Drilling test results for manufactured sand-soil I: (a) $0 \mathrm{MPa}^{-2}$; (b) $0.12 \mathrm{MPa}^{-3}$; (c) $0.18 \mathrm{MPa}^{-2}$; (d) $0.24 \mathrm{MPa}^{-4}$; (e) $0.42 \mathrm{MPa}^{-3}$.

When the confining pressure is fixed, the torque and bearing capacity decrease with the increase of water content $(5 \%$, $10 \%$, and $15 \%$ ); the slopes of the fitted curves show the difference under the three water content conditions. The influence of confining pressure on the slope of the model curve is different with different water contents. The slope 

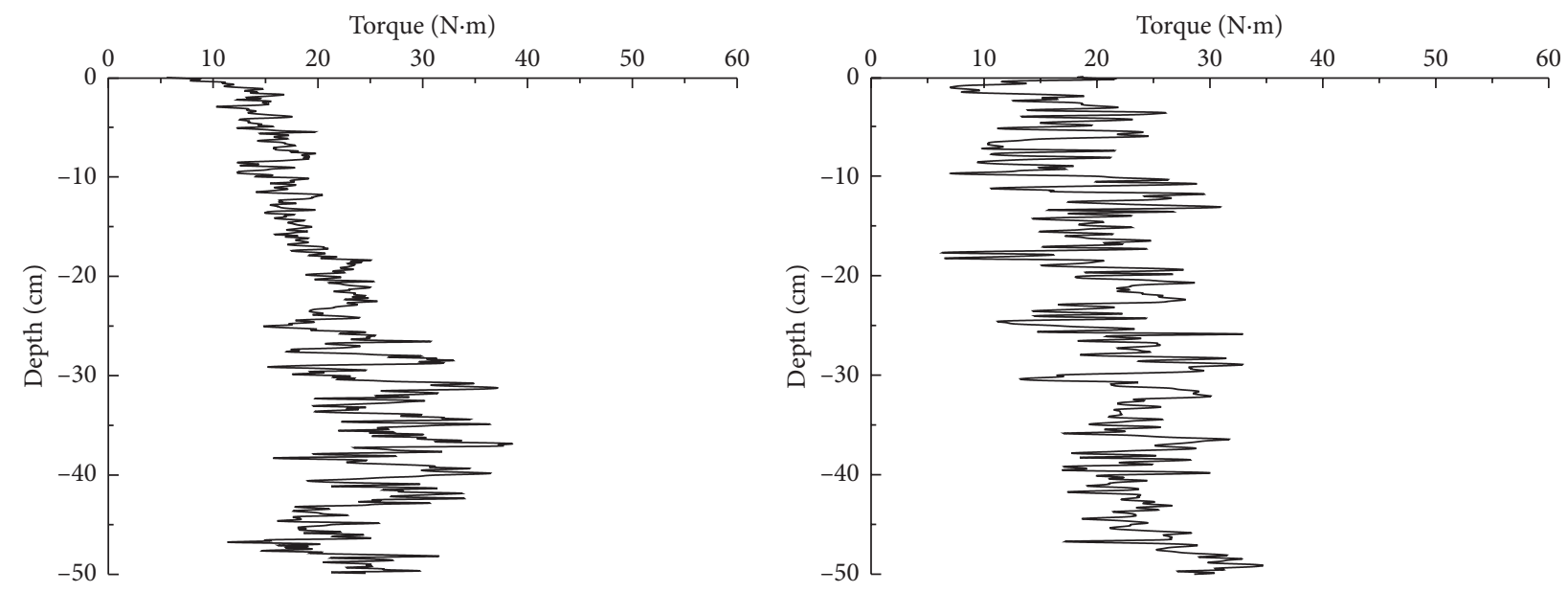

(a)

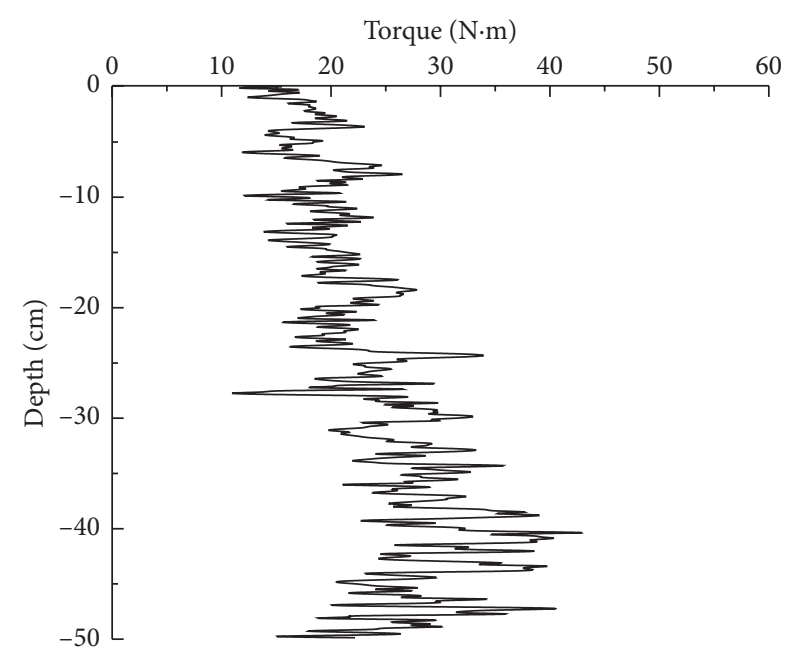

(c)

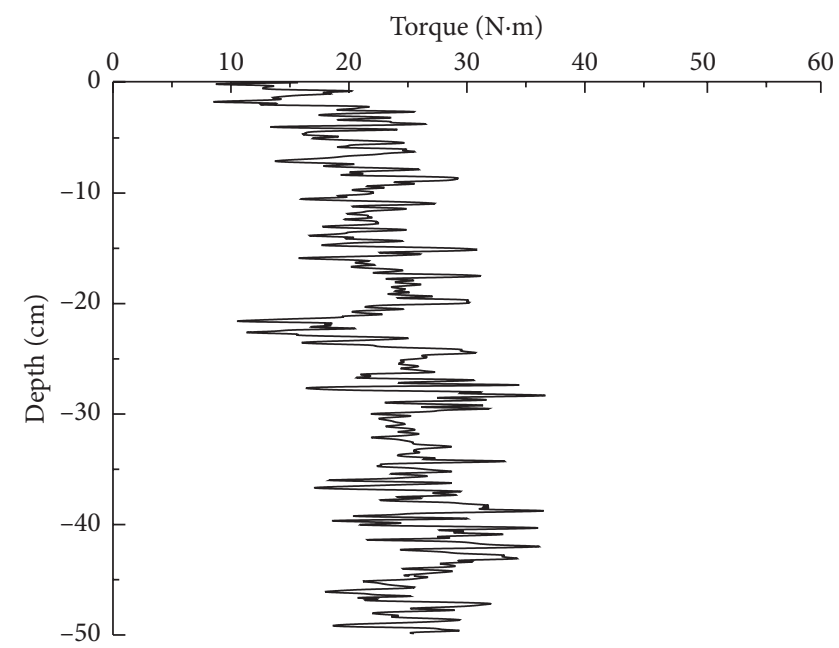

(d)

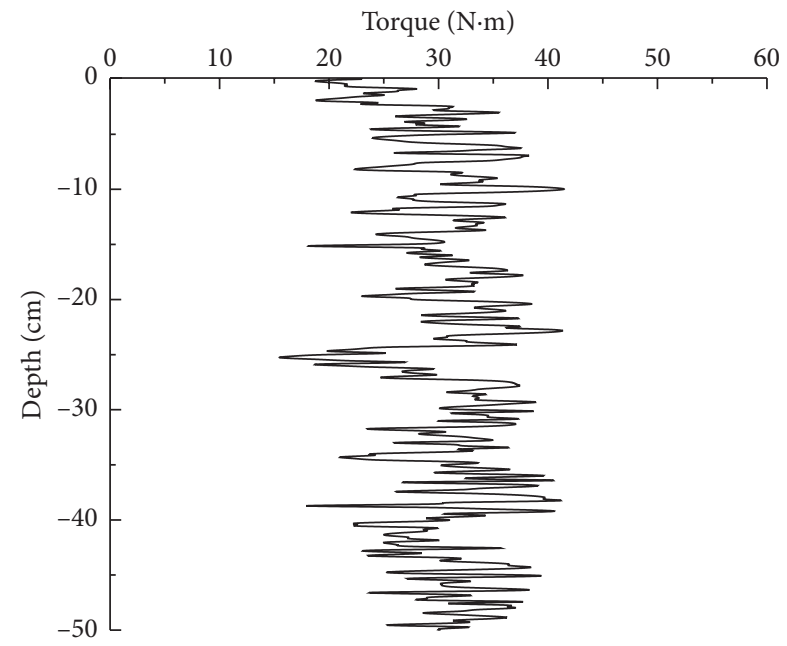

(e)

Figure 3: Drilling test results for manufactured sand-soil II: (a) $0 \mathrm{MPa}^{-2}$; (b) $0.12 \mathrm{MPa}^{-1}$; (c) $0.18 \mathrm{MPa}^{-4}$; (d) $0.24 \mathrm{MPa}^{-1}$; (e) $0.42 \mathrm{MPa}^{-2}$.

varies as follows: with $10 \%$ moisture content $>$ with $5 \%$ moisture content $>$ with $15 \%$ water content. This law can be further explained as the change in porosity (density) caused by confining pressure is different when the moisture content is different. It can be found after comparison that when the water content is $10 \%$, the confining pressure change can 


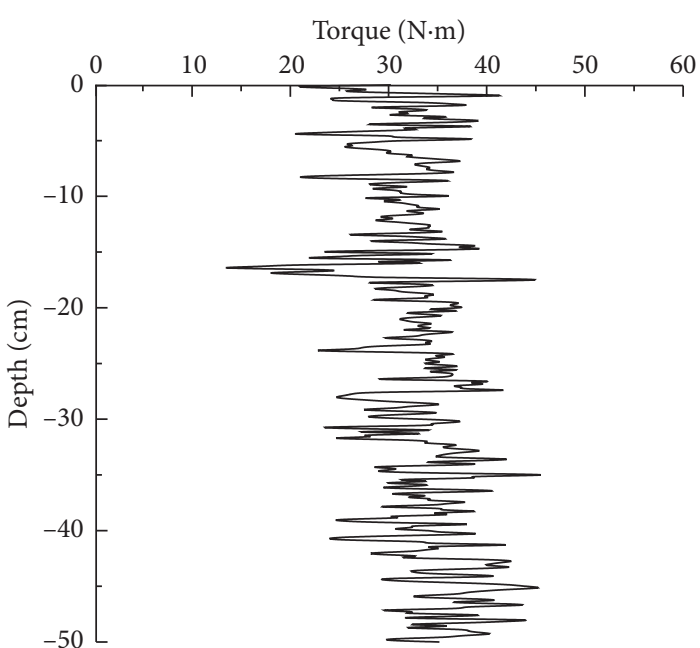

(a)

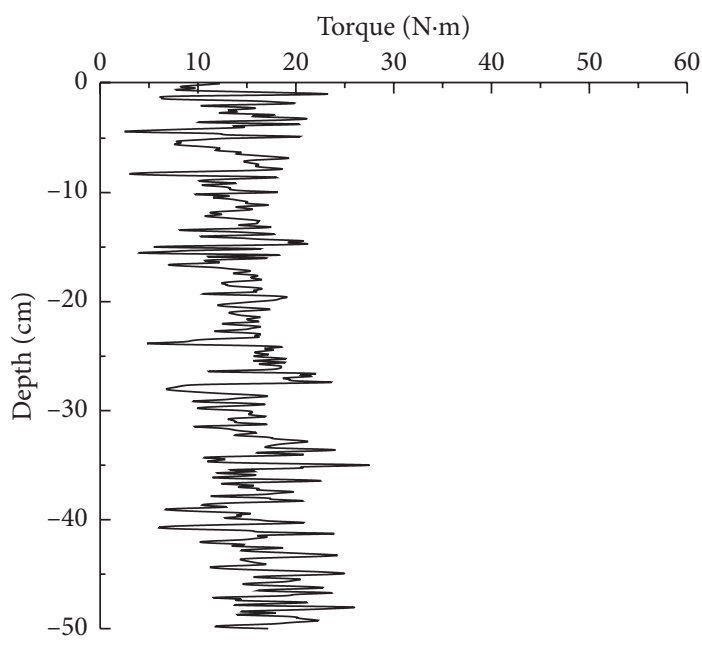

(c)

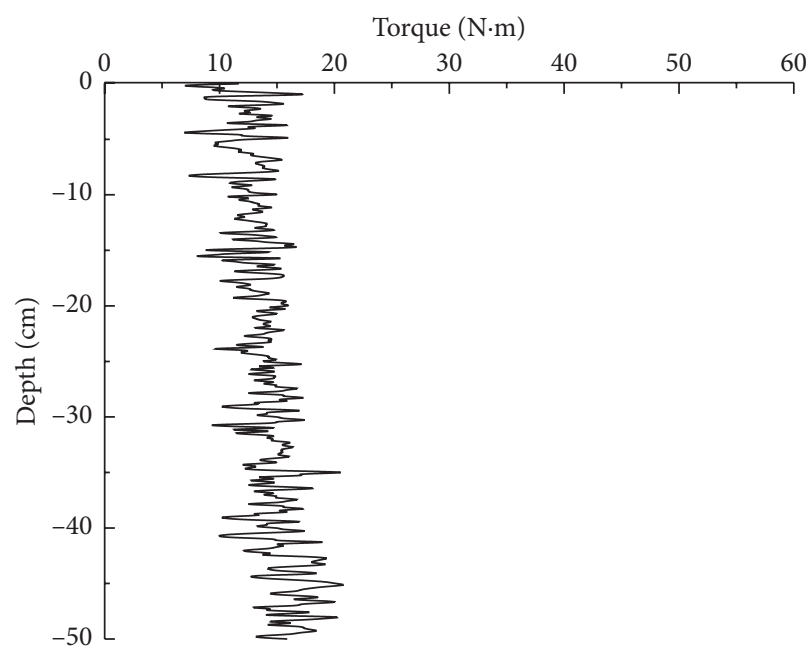

(b)

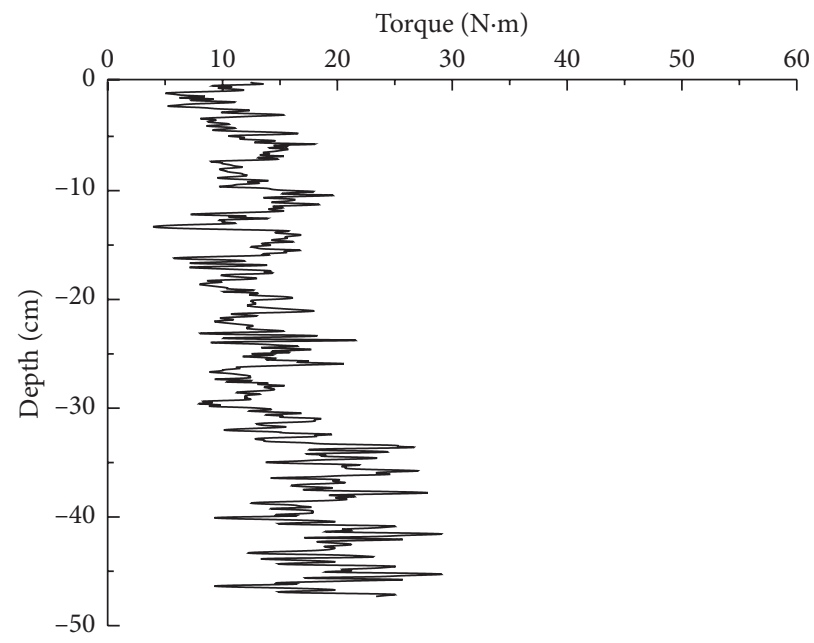

(d)

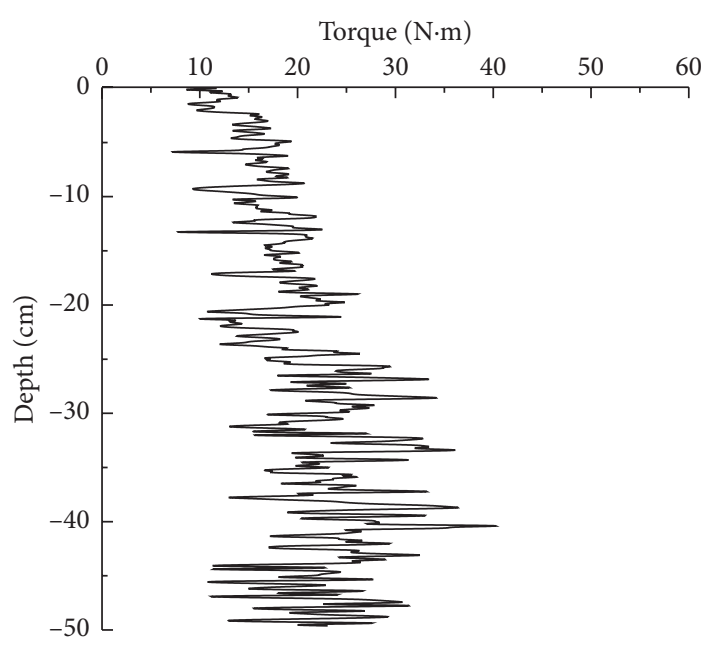

(e)

Figure 4: Drilling test results for manufactured sand-soil III: (a) $0 \mathrm{MPa}^{-1}$; (b) $0.12 \mathrm{MPa}^{-4}$; (c) $0.18 \mathrm{MPa}^{-1}$; (d) $0.24 \mathrm{MPa}^{-3}$; (e) $0.42 \mathrm{MPa}^{-1}$.

significantly reduce the manufactured sand-soil porosity without causing the uplift deformation of the soil; thus, the density of the manufactured sand-soil increases. The manufactured sand-soil with 5\% moisture content has lower initial porosity and higher density. The soil deformation is less when an external load is applied, and the change of 
TABLE 5: Test results of manufactured sand-soil I.

\begin{tabular}{|c|c|c|c|}
\hline Confining pressure $(\mathrm{MPa})$ & & Average torque $(\mathrm{N} \cdot \mathrm{m})$ & Bearing capacity $(\mathrm{kPa})$ \\
\hline \multirow{4}{*}{0} & No. 1 measuring point & 24.17 & 145 \\
\hline & No. 2 measuring point & 24.01 & 145 \\
\hline & No. 3 measuring point & 23.79 & 144 \\
\hline & No. 4 measuring point & 21.84 & 141 \\
\hline \multirow{4}{*}{0.12} & No. 1 measuring point & 28.92 & 184 \\
\hline & No. 2 measuring point & 29.23 & 185 \\
\hline & No. 3 measuring point & 25.85 & 169 \\
\hline & No. 4 measuring point & 27.46 & 173 \\
\hline \multirow{4}{*}{0.18} & No. 1 measuring point & 31.75 & 200 \\
\hline & No. 2 measuring point & 31.01 & 200 \\
\hline & No. 3 measuring point & 30.10 & 193 \\
\hline & No. 4 measuring point & 28.44 & 189 \\
\hline \multirow{4}{*}{0.24} & No. 1 measuring point & 34.51 & 232 \\
\hline & No. 2 measuring point & 35.21 & 232 \\
\hline & No. 3 measuring point & 33.12 & 229 \\
\hline & No. 4 measuring point & 35.74 & 235 \\
\hline \multirow{4}{*}{0.42} & No. 1 measuring point & 41.23 & 286 \\
\hline & No. 2 measuring point & 42.31 & 290 \\
\hline & No. 3 measuring point & 40.15 & 285 \\
\hline & No. 4 measuring point & 40.89 & 289 \\
\hline
\end{tabular}

TABLE 6: Test results of manufactured sand-soil II.

\begin{tabular}{|c|c|c|c|}
\hline Confining pressure $(\mathrm{MPa})$ & & Average torque $(\mathrm{N} \cdot \mathrm{m})$ & Bearing capacity $(\mathrm{kPa})$ \\
\hline \multirow{4}{*}{0} & No. 1 measuring point & 20.14 & 82 \\
\hline & No. 2 measuring point & 21.52 & 83 \\
\hline & No. 3 measuring point & 21.10 & 83 \\
\hline & No. 4 measuring point & 19.89 & 80 \\
\hline \multirow{4}{*}{0.12} & No. 1 measuring point & 22.70 & 106 \\
\hline & No. 2 measuring point & 22.42 & 106 \\
\hline & No. 3 measuring point & 21.01 & 104 \\
\hline & No. 4 measuring point & 22.95 & 108 \\
\hline \multirow{4}{*}{0.18} & No. 1 measuring point & 23.87 & 122 \\
\hline & No. 2 measuring point & 23.58 & 123 \\
\hline & No. 3 measuring point & 22.11 & 120 \\
\hline & No. 4 measuring point & 24.89 & 123 \\
\hline \multirow{4}{*}{0.24} & No. 1 measuring point & 25.10 & 137 \\
\hline & No. 2 measuring point & 25.24 & 136 \\
\hline & No. 3 measuring point & 22.17 & 131 \\
\hline & No. 4 measuring point & 23.20 & 134 \\
\hline \multirow{4}{*}{0.42} & No. 1 measuring point & 29.01 & 176 \\
\hline & No. 2 measuring point & 30.22 & 179 \\
\hline & No. 3 measuring point & 27.96 & 175 \\
\hline & No. 4 measuring point & 30.73 & 176 \\
\hline
\end{tabular}

confining pressure has little effect on the soil density. When the moisture content is $15 \%$, the soil has high porosity and is easy to deform when subjected to external force. Compared to manufactured sand-soil models with $5 \%$ and $10 \%$ moisture content levels, the effect of confining pressure on porosity is not obvious.

\section{Verification of Engineering Bearing Capacity Based on the W-T-BC Test Model}

5.1. Overview of the High-Fill Subgrade of Taihang Mountains Expressway. The Taihang Mountains Expressway Project is a major roadway construction project to undertake Beijing's noncapital functions. The subgrade of a certain section of the project was filled with the manufactured sand-soil prepared with the gravel soil excavated beside a tunnel. According to the engineering survey data, the moisture content of the manufactured sand-soil was $11.2 \%$, the weight was $20.9 \mathrm{kN} /$ $\mathrm{m}^{3}$, and the standard value of bearing capacity was $120 \mathrm{kPa}$. To ensure the quality of the project, an inspection of the subgrade of the Xingtai section was carried out.

5.2. Verification Method and Procedure. The field measurement of bearing capacity is carried out by rotary 
TABLE 7: Test results of manufactured sand-soil III.

\begin{tabular}{|c|c|c|c|}
\hline Confining pressure $(\mathrm{MPa})$ & & Average torque $(\mathrm{N} \cdot \mathrm{m})$ & Bearing capacity $(\mathrm{kPa})$ \\
\hline \multirow{4}{*}{0} & No. 1 measuring point & 9.51 & 35 \\
\hline & No. 2 measuring point & 10.00 & 35 \\
\hline & No. 3 measuring point & 8.49 & 32 \\
\hline & No. 4 measuring point & 11.43 & 36 \\
\hline \multirow{4}{*}{0.12} & No. 1 measuring point & 12.51 & 51 \\
\hline & No. 2 measuring point & 13.14 & 50 \\
\hline & No. 3 measuring point & 13.67 & 50 \\
\hline & No. 4 measuring point & 12.13 & 48 \\
\hline \multirow{4}{*}{0.18} & No. 1 measuring point & 14.20 & 58 \\
\hline & No. 2 measuring point & 14.80 & 59 \\
\hline & No. 3 measuring point & 12.47 & 54 \\
\hline & No. 4 measuring point & 16.85 & 60 \\
\hline \multirow{4}{*}{0.24} & No. 1 measuring point & 15.84 & 75 \\
\hline & No. 2 measuring point & 16.45 & 75 \\
\hline & No. 3 measuring point & 17.58 & 76 \\
\hline & No. 4 measuring point & 14.33 & 72 \\
\hline \multirow{4}{*}{0.42} & No. 1 measuring point & 22.92 & 98 \\
\hline & No. 2 measuring point & 21.85 & 98 \\
\hline & No. 3 measuring point & 23.12 & 101 \\
\hline & No. 4 measuring point & 23.45 & 103 \\
\hline
\end{tabular}

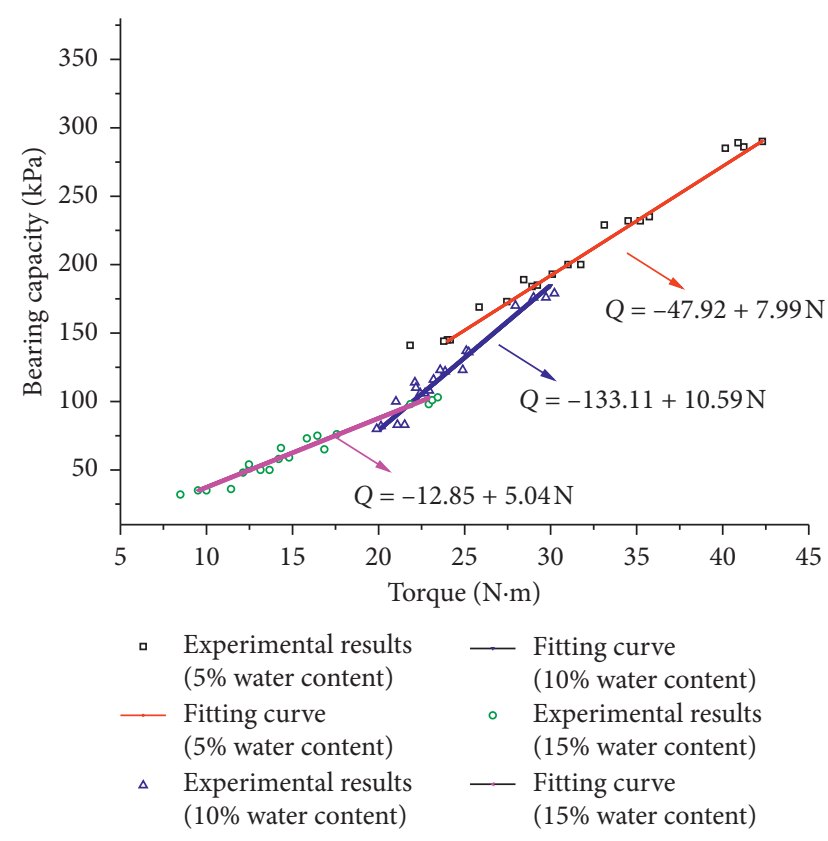

Figure 5: The relationship between shear strength and normal stress of the test samples.

penetration test and light dynamic penetration test. Three points on the center line of subgrade are selected for the experiment, one rotary penetration test and two light dynamic penetration tests for each point. The layout of measuring points is shown in Figure 6.

Three sets of rotary penetration tests with a drilling depth of $2.5 \mathrm{~m}$ were carried out first, as shown in Figure 7 . The drilling speed was $500 \mathrm{r} \cdot \mathrm{min}^{-1}$, the drilling rate was $15 \mathrm{~cm} /$ min, the maximum propulsion was $10 \mathrm{kN}$, and a thin diamond drill with a diameter of $4 \mathrm{~cm}$ was used. During the

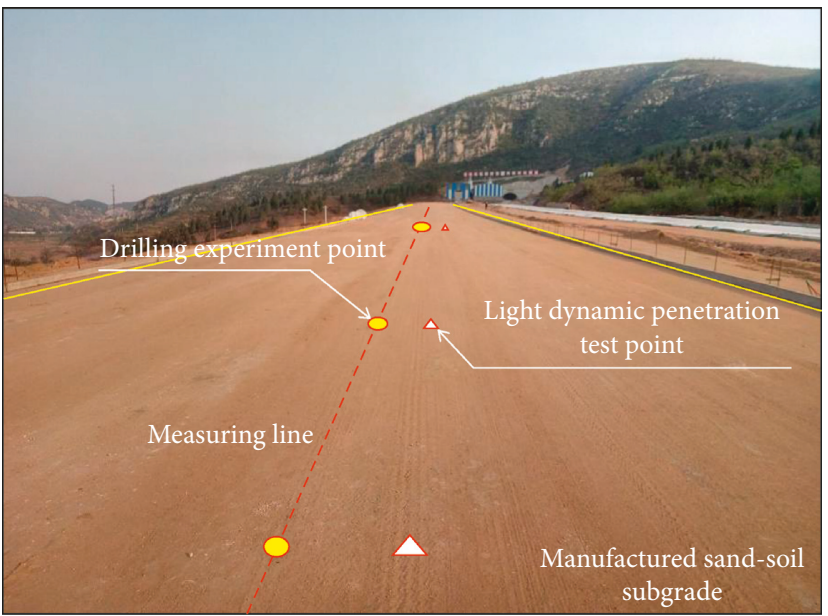

FIGURE 6: Layout of measuring points.

drilling process, the computer collected and recorded the measured torque in real time. A panoramic stereo imaging system was used to obtain the shape of the drill hole wall. The light dynamic penetration test method was conducted after borehole observation. Two sets of experiments were carried out at each point with a drilling depth of $2.5 \mathrm{~m}$, and the light dynamic penetration point is within $1.5 \mathrm{~m}$ of the borehole.

5.3. Detection Results Based on Two Methods. Table 8 shows the torque and bearing capacity of different layers of the subgrade in the three sets of experiments. Taking the first point as an example, the soil is divided into three layers: depth of $0-60 \mathrm{~cm}$ had an average torque of $23.54 \mathrm{~N} \cdot \mathrm{m}$, depth of $60-180 \mathrm{~cm}$ had an average torque of $18.08 \mathrm{~N} \cdot \mathrm{m}$, and a depth of $180-250 \mathrm{~cm}$ had an average torque of $26.08 \mathrm{~N} \cdot \mathrm{m}$. The indoor experiment shows that 


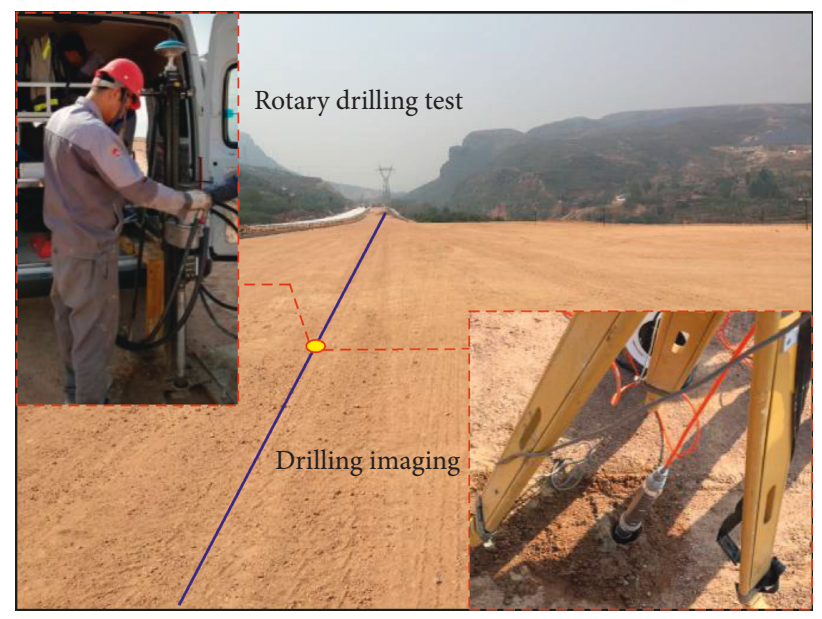

FIgURE 7: Rotary penetration field test.

TABLE 8: Test results of manufactured sand-soil III.

\begin{tabular}{lccc}
\hline & Depth $(\mathrm{cm})$ & Average torque $(\mathrm{N} \cdot \mathrm{m})$ & Bearing capacity $(\mathrm{kPa})$ \\
\hline \multirow{3}{*}{ No. 1 measuring point } & $0-0.58$ & 23.53 & 116.07 \\
& $0.58-162$ & 18.08 & 58.35 \\
\hline \multirow{2}{*}{ No. 2 measuring point } & $150-250$ & 26.08 & 142.59 \\
& $0-77$ & 22.51 & 105.23 \\
\hline \multirow{2}{*}{ No. 3 measuring point } & $77-176$ & 18.89 & 66.96 \\
& $176-250$ & 24.54 & 126.75 \\
\hline
\end{tabular}

the water content of the manufactured sand-soil in the subgrade is $10.8 \%$ and the dry density is 1.71 . Using the empirical formula with a water content of $10 \%$ to calculate the bearing capacity, the results corresponding to the three layers of soil are $116.07 \mathrm{kPa}$, $58.35 \mathrm{kPa}$, and $142.59 \mathrm{kPa}$, respectively.

Figure 8 shows the relationship between the torque of the rotary penetration mechanical response and changes in the shape of the borehole wall at the first point. It can be seen from the figure that the drilling torque increases with depth $(0-58 \mathrm{~cm})$ and is stable around $23.54 \mathrm{~N} \cdot \mathrm{m}$. The corresponding borehole wall is not loose or hollow, and the fracture is relatively neat. At the depth of $58 \sim 162 \mathrm{~cm}$, the torque decreases with the increase of depth and the data fluctuation is more significant. The average torque is $18.08 \mathrm{~N} \cdot \mathrm{m}$. The borehole wall of this area shows obvious roughness, and the soil compactness is low. The drilling torque increases steadily with the depth within the depth range of $162 \sim 250 \mathrm{~cm}$, the average torque is $26.08 \mathrm{~N} \cdot \mathrm{m}$, and the borehole wall of the corresponding area is smooth and flat with high density.

The light dynamic penetration test was carried out 6 times in total. The depth stratification and bearing capacity test values at each point are shown in Table 9.

\subsection{Comparison between Standard Values and Calculated} Values of W-T-BC Model. Figure 9 shows the comparison of the calculated bearing capacity of the W-T-BC model and the experimental results of the light dynamic penetration test. Figure 9(a) shows the comparison between the values of the $\mathrm{W}$-T-BC model and the measured standard values. As can be seen from the figure, the measured values of the three sets of bearing capacity are stably distributed in the W-T-BC model, with minimal fluctuation. Figure 9(b) numerically analyzes the difference between the results of the model method and the standard method. The numerical difference rates of the eight groups are 95.43\%, 93.23\%, 94.67\%, $96.51 \%, 86.97 \%, 92.18 \%, 93.09 \%$, and $93.77 \%$. The average difference rate is $6.77 \%$, which is less than $10 \%$, indicating the accuracy and effectiveness of the $\mathrm{W}-\mathrm{T}-\mathrm{BC}$ model.

Figure 10 compares the designed value of the bearing capacity of manufactured sand-soil subgrade $(120 \mathrm{kPa})$, the standard value of the dynamic penetration test, and the calculated value of the $\mathrm{W}-\mathrm{T}-\mathrm{BC}$ model $(10 \%$ water content). The figure shows that when the torque value is $23.90 \mathrm{~N} \cdot \mathrm{m}$, the calculated value of the bearing capacity in the $\mathrm{W}-\mathrm{T}-\mathrm{BC}$ model is $120 \mathrm{kPa}$ and the six sets of dynamic penetration test values are distributed around this value with minimal fluctuation. This indicates that the manufactured sand-soil subgrade in this stratum has good engineering properties and no failure characteristics. The second layer of test point 1 and the second layer of test point 2 have a bearing capacity of less than $120 \mathrm{kPa}$, showing obvious failure characteristics.

5.5. New Understanding of the Interaction between Manufactured Sand and Soil Particles. In Figure 11, the large 


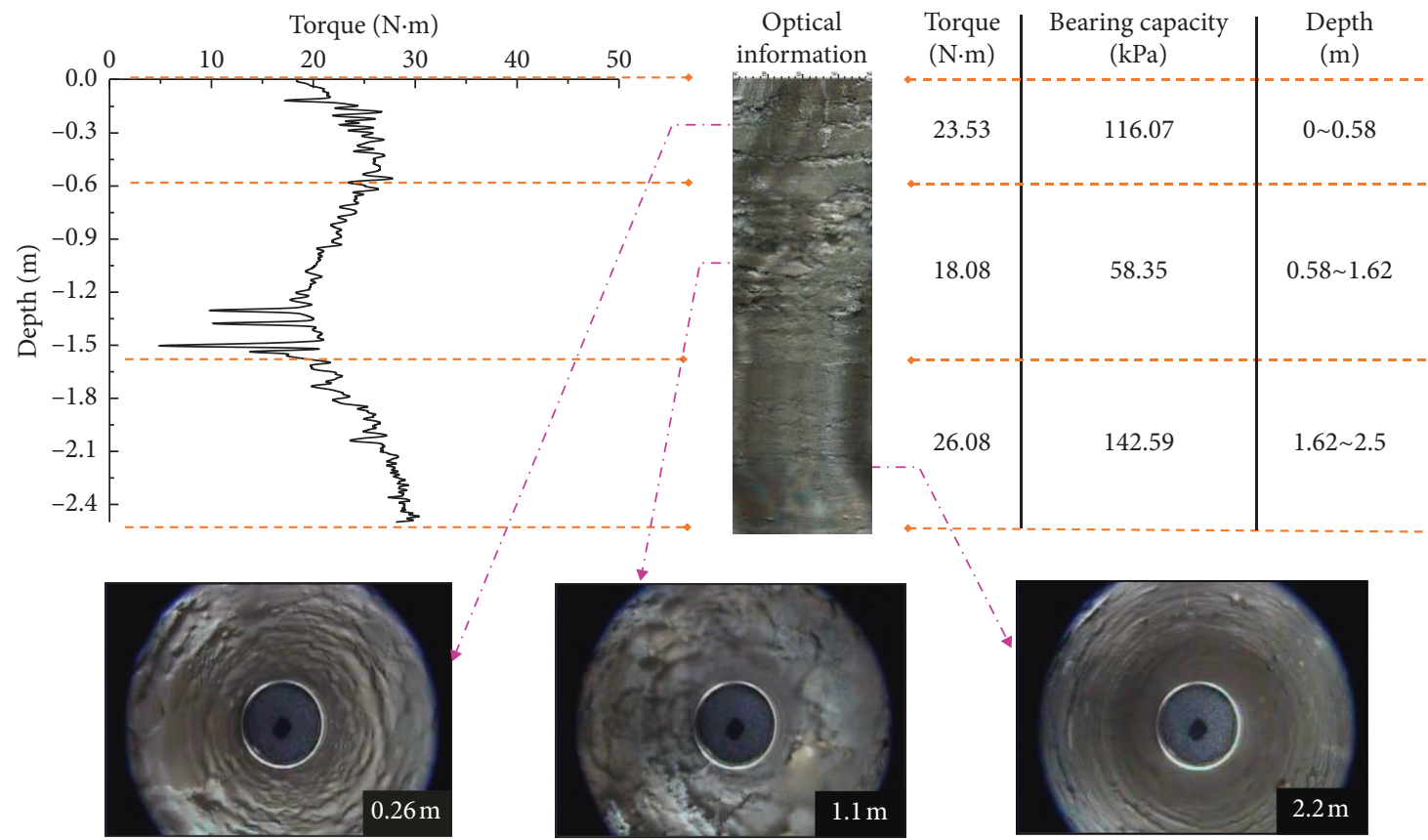

FIGURE 8: Drilling test results of the road.

TABLE 9: Test results of manufactured sand-soil III.

Point 1

Point 2

Depth $(\mathrm{cm})$ Total impact times Bearing capacity $(\mathrm{kPa})$ Depth $(\mathrm{cm})$ Total impact times Bearing capacity $(\mathrm{kPa})$

\begin{tabular}{|c|c|c|c|c|c|c|}
\hline \multirow{3}{*}{ No. 1 measuring point } & $0-60$ & 16 & 105 & $0-60$ & 17 & 112 \\
\hline & $60-160$ & 10 & 62 & $60-160$ & 9 & 58 \\
\hline & $160-250$ & 20 & 135 & $160-250$ & 20 & 135 \\
\hline \multirow{3}{*}{ No. 2 measuring point } & $0-80$ & 17 & 113 & $0-80$ & 16 & 105 \\
\hline & $80-175$ & 11 & 67 & $80-175$ & 12 & 74 \\
\hline & $175-250$ & 19 & 129 & $175-250$ & 20 & 135 \\
\hline \multirow{2}{*}{ No. 3 measuring point } & $0-180$ & 18 & 120 & $0-180$ & 17 & 112 \\
\hline & $180-250$ & 21 & 140 & $180-250$ & 20 & 135 \\
\hline
\end{tabular}

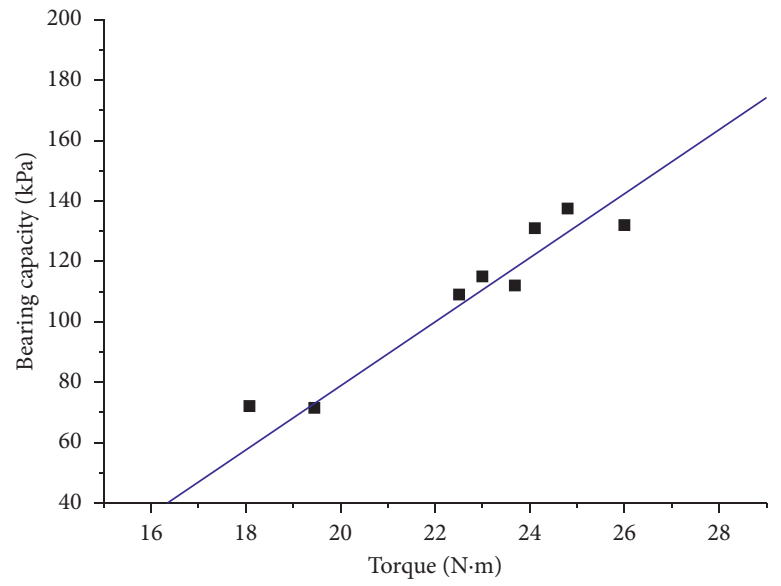

W-T-BC model (15\% water content)

- Test standard values

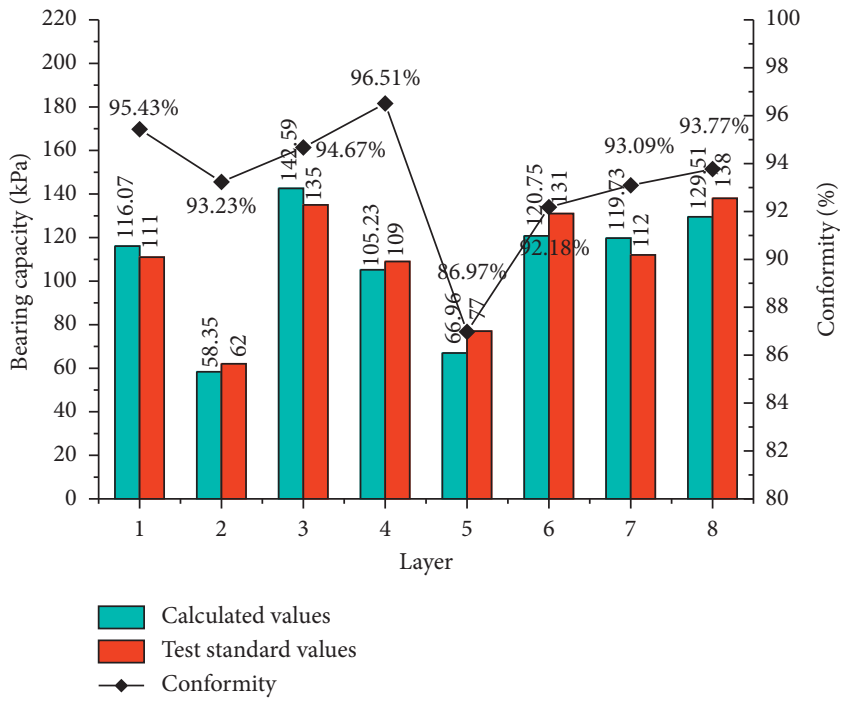

(b)

FiguRE 9: Comparison of two experimental results. 


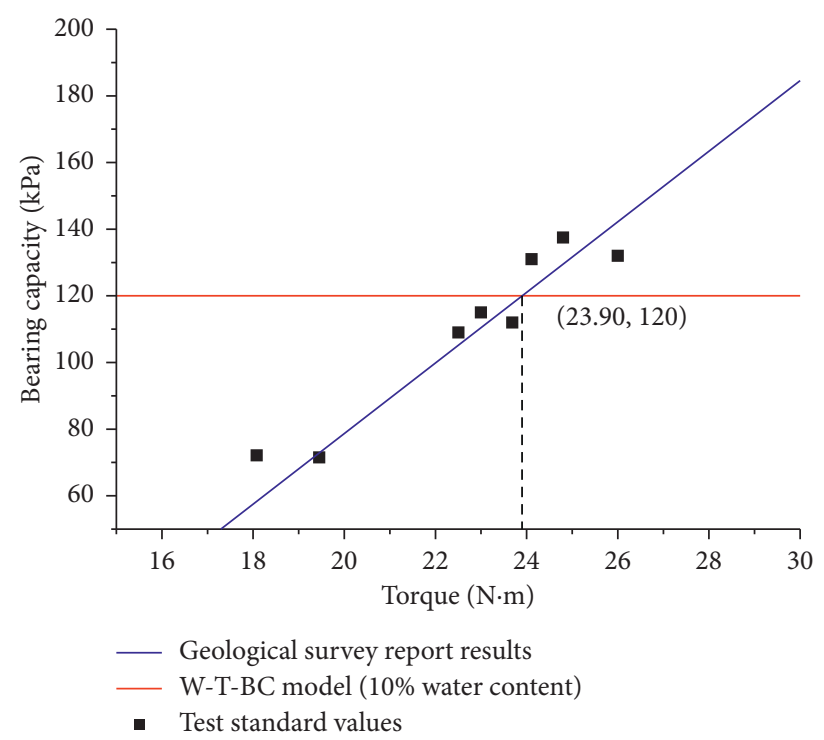

FIgURE 10: Comparison of three experimental results.
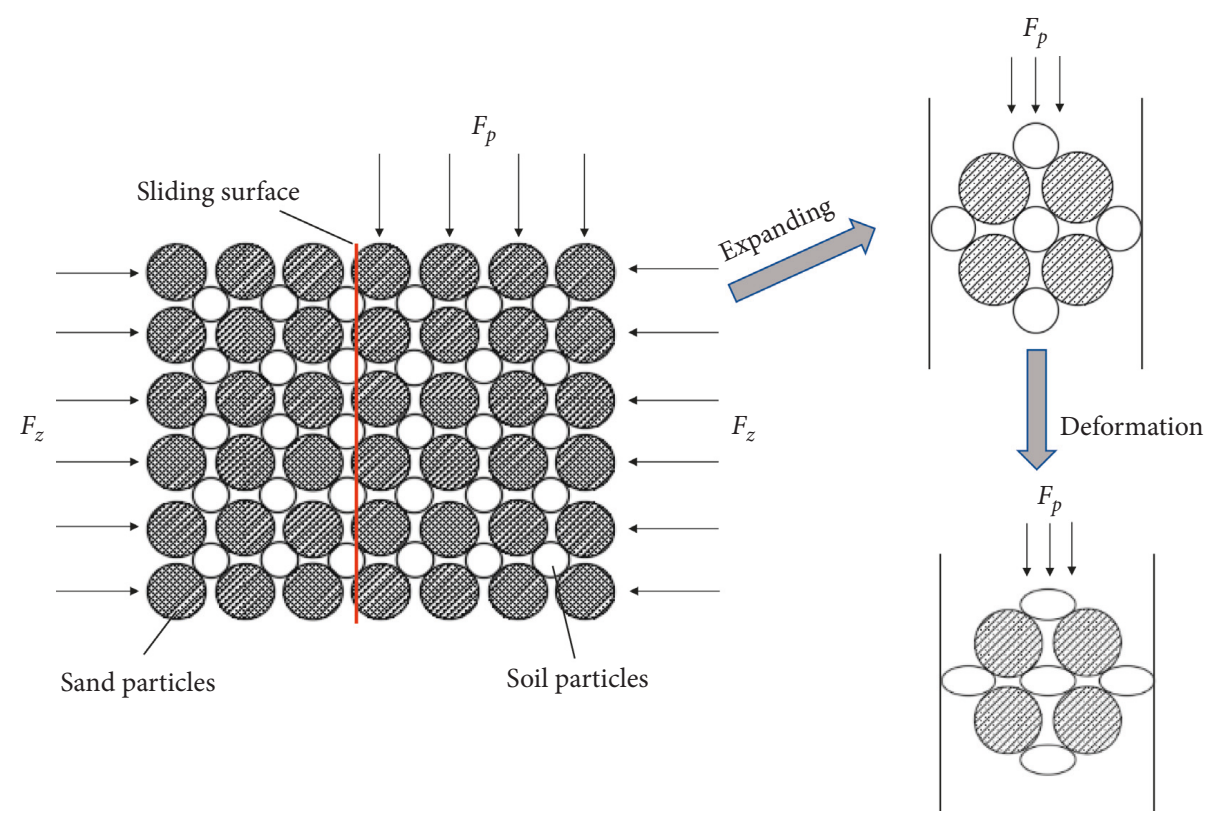

FIgURE 11: Microscopic force-deformation diagram of manufactured sand-soil.

black particle is a sand particle and the white small particle is a soil particle. The effect of pore water in the manufactured sand-soil is neglected. The simplified manufactured sand-soil microclay is the ideal mosaic structure of sand and soil particles. The sand and soil particles are adhesively bonded to form a sand-soil rigid interface nest. Figures 11 and 12 are schematic diagrams of the microscopic force-deformation of the manufactured sand-soil and homogeneous soil. In the laterally confined state, the manufactured sand-soil receives the vertical load. Due to the bonding action of the sand-soil interface and the rigid support of sands, the sand-soil particles have larger frictional resistance and smaller compression volume compared to the homogeneous soil. Therefore, the deformation of the manufactured sand-soil settlement deformation is smaller and shearing and cracking are less likely to occur.

\section{Conclusion}

In this study, the following conclusions were obtained by studying the quantitative relationship between the mechanical response and the bearing capacity of the manufactured sand-soil in digital rotary penetration:

(1) Based on the simplified quantitative relationship between the torque and the bearing capacity of the rock and soil $\left([P]=K^{\prime} t\right)$, the rotary penetration test 


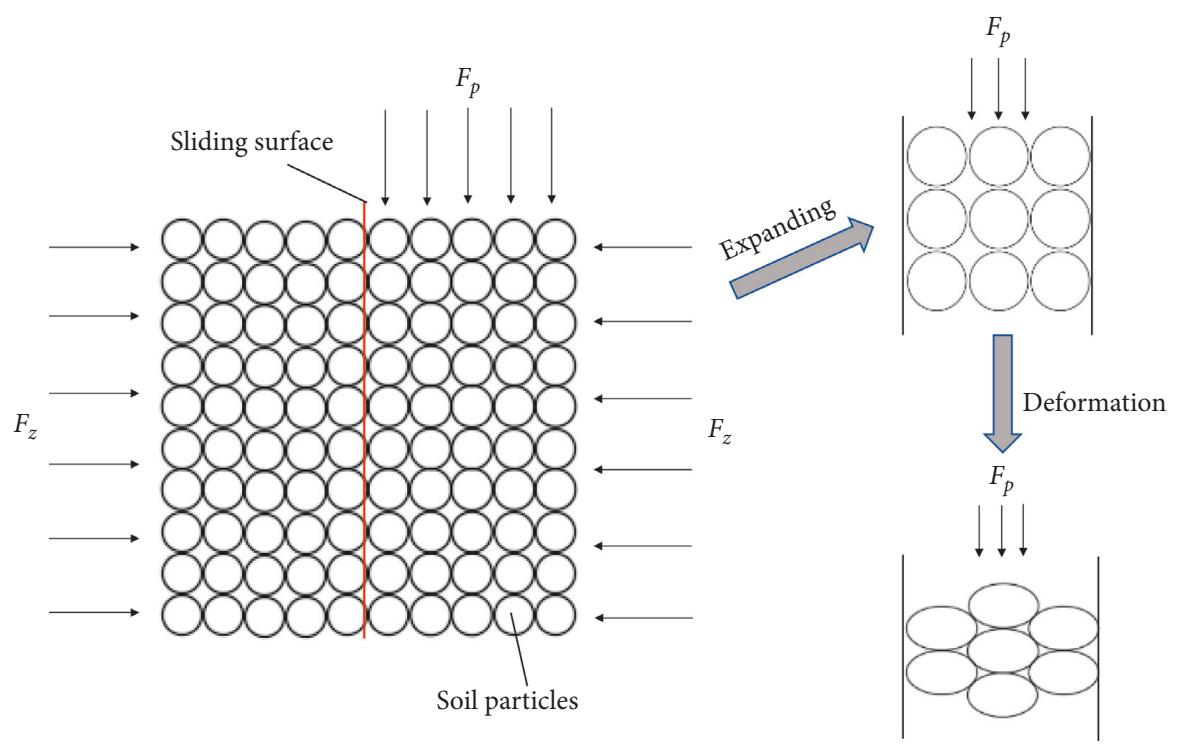

Figure 12: Microscopic force-deformation diagram of homogeneous soil.

of the manufactured sand-soil model with different moisture content levels of $5 \%, 10 \%$, and $15 \%$ was carried out using the custom-made testing device for the intensity parameters of the rock-soil mass. The relationship between the drilling torque $(N)$ and the sand-soil bearing capacity $(Q)$ was studied, and the W-T-BC relationship model was established: $Q=-47.92$ $+7.99 \mathrm{~N}$ (water content of 5\%, N: 20 50), $Q=-133.11+$ $10.59 \mathrm{~N}$ (water content of $10 \%, \mathrm{~N}: 15 \sim 30$ ), and $Q=-12.85+5.04 \mathrm{~N}$ (water content of $15 \%, \mathrm{~N}: 10 \sim 25$ ).

(2) The slope of the model curve was analyzed. With moisture content levels of $5 \%, 10 \%$, and $15 \%$, the slope is $10 \%$ moisture content $>5 \%$ moisture content $>15 \%$ moisture content. When the water content levels are different, the effect of confining pressure on the change of sand-soil porosity and the difficulty of sand deformation is different.

(3) Simplified manufactured sand-soil microclay is a mosaic structure of sand and soil particles. Sand-soil constitutes a rigid-soft interface grip body. Due to the bonding action of the sand-soil interface and the rigid support of sands, the sand-soil particles have larger frictional resistance and smaller settlement deformation compared to the homogeneous soil. Therefore, shearing and cracking are less likely to occur. The engineering mechanics of sand-soil particle interaction is revealed.

(4) The W-T-BC model is suitable for sands with the same sand-soil particle size, gradation, and water content, as in this study. The model still needs to be modified for different site conditions to meet the engineering reliability requirements.

\section{Data Availability}

The data used to support the findings of this study are available from the corresponding author upon request.

\section{Conflicts of Interest}

The authors declare that they have no conflicts of interest.

\section{Acknowledgments}

This work was supported by Beijing Talent Foundation (Project number: 2017000021223ZK04), National Natural Science Foundation of China (Project number: 51504029 and 51774048), and Fundamental Research Funds for the Central Universities (FRF-BD-19-004A).

\section{References}

[1] W. W. Yang, Z. Q. Yue, and G. Thaml, "Automatic monitoring of inserting or retrieving SPT sampler in drillhole," Geotechnical Testing Journal, vol. 35, no. 3, Article ID 103450, 2012.

[2] M. W. Gui, K. Soga, M. D. Bolton, and J. P. Hamelin, "Instrumented borehole drilling for subsurface investigation," Journal of Geotechnical and Geoenvironmental Engineering, vol. 128, no. 4, pp. 283-291, 2002.

[3] S. Hamelin, N. Bilgin, and C. Feridunoglu, "Dominant rock properties affecting the penetration rate of percussive drills," International Journal of Rock Mechanics and Mining Sciences, vol. 40, no. 5, pp. 711-723, 2003.

[4] Y. M. Jan and R. L. J. Campbell, "Borehole correction of MWD gamma ray and resistivity logs," in Proceedings of the Transactions of the SPWLA Annual Logging Symposium, pp. 189-197, Society of Professional Well Log Analysts Inc., Houston, TX, USA, 1984.

[5] I. A. Dowell, P. L. York, and C. E. Jackson, "Evolution of an LWD toolstring with applications for petrophysical logging and drilling control," in Proceedings of Annual Offshore Technology Conference, Field Drilling and Development Systems, pp. 897-905, Houston, TX, USA, May 1993.

[6] J. Signorelli and T. Wang, "Finite-difference modeling of electromagnetic tool response for logging while drilling," Geophysics, vol. 69, no. 1, pp. 152-160, 2004.

[7] H. Tian, S. C. Li, L. G. Xue, D. H. Qiu, M. X. Su, and K. Wang, "Identification of interface of tuff stratum and classification of 
surrounding rock of tunnel using drilling energy theory," Rock and Soil Mechanics, vol. 33, no. 8, pp. 2457-2464, 2012.

[8] S. S. Gao, "Coring process monitoring for strength of grout, concrete and rock in laboratory," Master's thesis, The University of Hong Kong, Hong Kong, 2010.

[9] P. Pfister, "Recording drilling parameters in ground engineering," International Journal of Rock Mechanics and Mining Sciences \& Geomechanics Abstracts, vol. 23, no. 2, p. 52, 1985.

[10] Z. Z. Cao, H. D. Liu, X. M. Yuan, and T. L. Youd, "Reliability of Chinese dynamic penetration test for liquefaction evaluation of gravelly soils," Chinese Journal of Geotechnical Engineering, vol. 38, no. 1, pp. 163-169, 2016.

[11] F. Dahl, A. Bruland, P. D. Jakobsen, B. Nilsen, and E. Grøv, "Classifications of properties influencing the drillability of rocks, based on the NTNU/SINTEF test method," Tunnelling and Underground Space Technology, vol. 28, pp. 150-158, 2012.

[12] H. Schunnesson, "RQD predictions based on drill performance parameters," Tunnelling and Underground Space Technology, vol. 11, no. 3, pp. 345-351, 1996.

[13] H. Karasawa, T. Ohno, M. Kosugi, and J. C. Rowley, "Methods to estimate the rock strength and tooth wear while drilling with roller-bits-part 1: milled-tooth bits," Journal of Energy Resources Technology, vol. 124, no. 3, pp. 125-132, 2002.

[14] Z. Q. Yue, "Drilling process monitoring for refining and upgrading rock mass quality classification methods," Chinese Journal of Rock Mechanics and Engineering, vol. 33, no. 10, pp. 1977-1996, 2014.

[15] J. Chen and Z. Q. Yue, "DPM system based detection and characterization of weak zones in weathered rock," Journal of Engineering Geology, vol. 19, no. 1, pp. 93-98, 2011.

[16] Z. Y. Tan, M. F. Cai, Z. Q. Yue, L. G. Tham, and C. F. Lee, "Theory and method of formation interface identification based on rock drillability index," Journal of University of Science and Technology Beijing, vol. 28, no. 9, pp. 803-807, 2006.

[17] L. Song, N. Li, and F. Y. Liu, "Research on applicable feasibility of rotary penetration technique in harder strata," Rock and Soil Mechanics, vol. 32, no. 2, pp. 635-640, 2011.

[18] L. Song, N. Li, and F. Y. Liu, "Research on intrinsic relationships among parameters of rotary penetration test in soft rock," Journal of Xi'an University of Technology, vol. 27, no. 1, pp. 24-30, 2011.

[19] Q. Wang, Q. Qin, S. Gao et al., "Relationship between rock drilling parameters and rock uniaxial compressive strength based on energy analysis," Journal of China Coal Society, vol. 43, no. 5, pp. 1289-1295, 2018.

[20] X. Lv, H. Zhou, and L. Xu, "Study on the quantitative relationship between soil in situ strength and drilling parameters," Environmental Earth Sciences, vol. 77, no. 12, 2018.

[21] P. Rai, H. Schunesson, P.-A. Lindqvist, and U. Kumar, "An overview on measurement-while-drilling technique and its scope in excavation industry," Journal of the Institution of Engineers (India): Series D, vol. 96, no. 1, pp. 57-66, 2015.

[22] A. Naeimipour, J. Rostamib, I. S. Buyuksagis, and O. Frough, "Estimation of rock strength using scratch test by a miniature disc cutter on rock cores or inside boreholes," International Journal of Rock Mechanics and Mining Sciences, vol. 107, pp. 9-18, 2018.

[23] G. Frough, G. Anna, and S. Håkan, "Development of a geological model for chargeability assessment of borehole using drill monitoring technique," International Journal of Rock Mechanics and Mining Sciences, vol. 109, pp. 9-18, 2018.
[24] G. Finfinger, S. Peng, Q. Gu, G. Wilson, and B. Thomas, "An approach to identifying geological properties from roof bolter drilling parameters," in Proceedings of the 19th International Conference on Ground Control in Mining, pp. 1-12, West Virginia University, Morgantown, WV, USA, August 2000.

[25] E. Yasar, P. G. Ranjth, and D. R. Viete, "An experimental investigation into the drilling and physico-mechanical properties of a rock-like brittle material," Journal of Petroleum Science and Engineering, vol. 76, no. 3-4, pp. 185-193, 2011.

[26] S. A. Aalizad and F. Rashidinejad, "Prediction of penetration rate of rotary-percussive drilling using artificial neural networks-a case study," Archives of Mining Sciences, vol. 57, no. 3, pp. 715-728, 2012.

[27] M. Mostofi, V. Rasouli, and E. Mawuli, "An estimation of rock strength using a drilling performance model: a case study in blacktip field, Australia," Rock Mechanics and Rock Engineering, vol. 44, no. 3, pp. 305-316, 2011.

[28] ASTM, Annual Book of ASTM Standards: Soils and Rock Division, ASTM, West Conshohocken, PA, USA, 1998.

[29] A. S. A. Rashid, M. G. Shirazi, H. Mohamad, and F. Sahdi, "Bearing capacity of sandy soil treated by Kenaf fibre geotextile," Environmental Earth Sciences, vol. 76, no. 12, 2017.

[30] R. Moradi, A. Marto, A. S. A. Rashid, M. M. Moradi, A. A. Ganiyu, and S. Horpibulsuk, "Bearing capacity of soft soil model treated with end-bearing bottom ash columns," Environmental Earth Sciences, vol. 77, no. 3, 2018. 


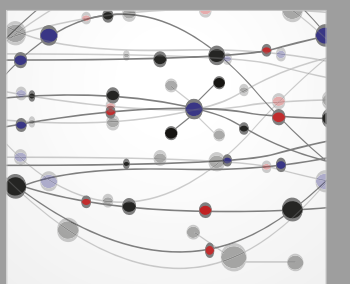

The Scientific World Journal
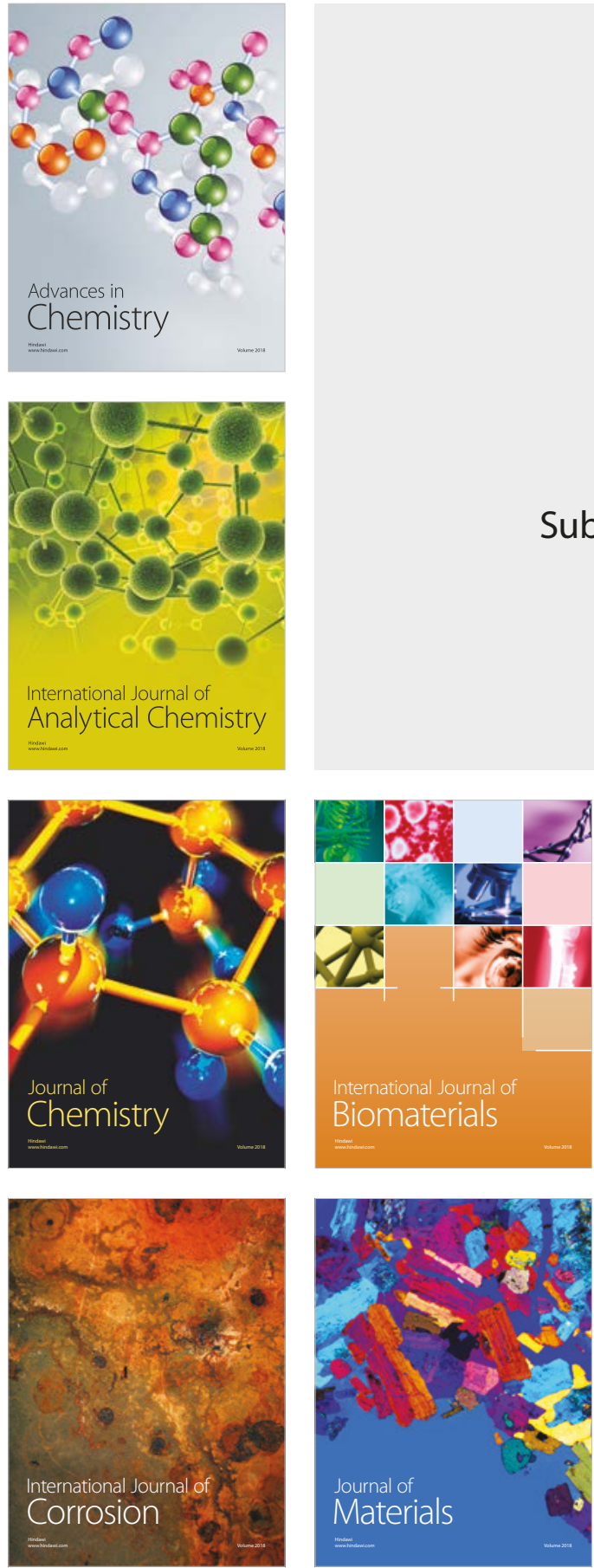

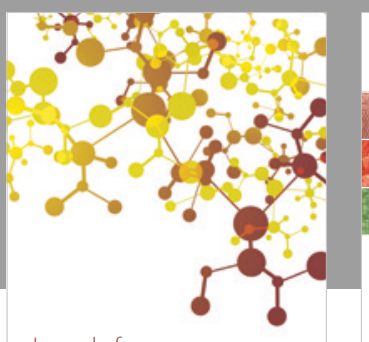

Journal of

Applied Chemistry
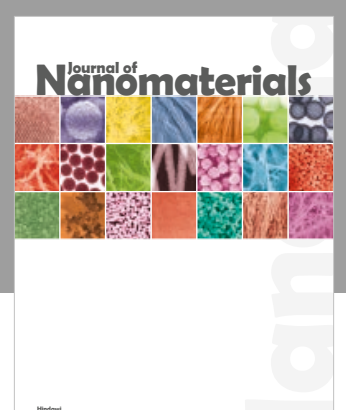

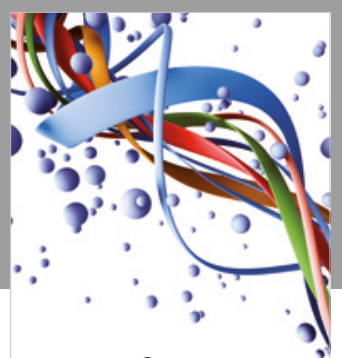

Scientifica

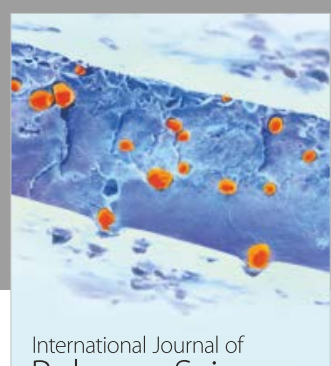

Polymer Science

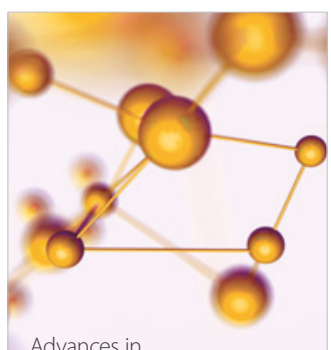

Physical Chemistry
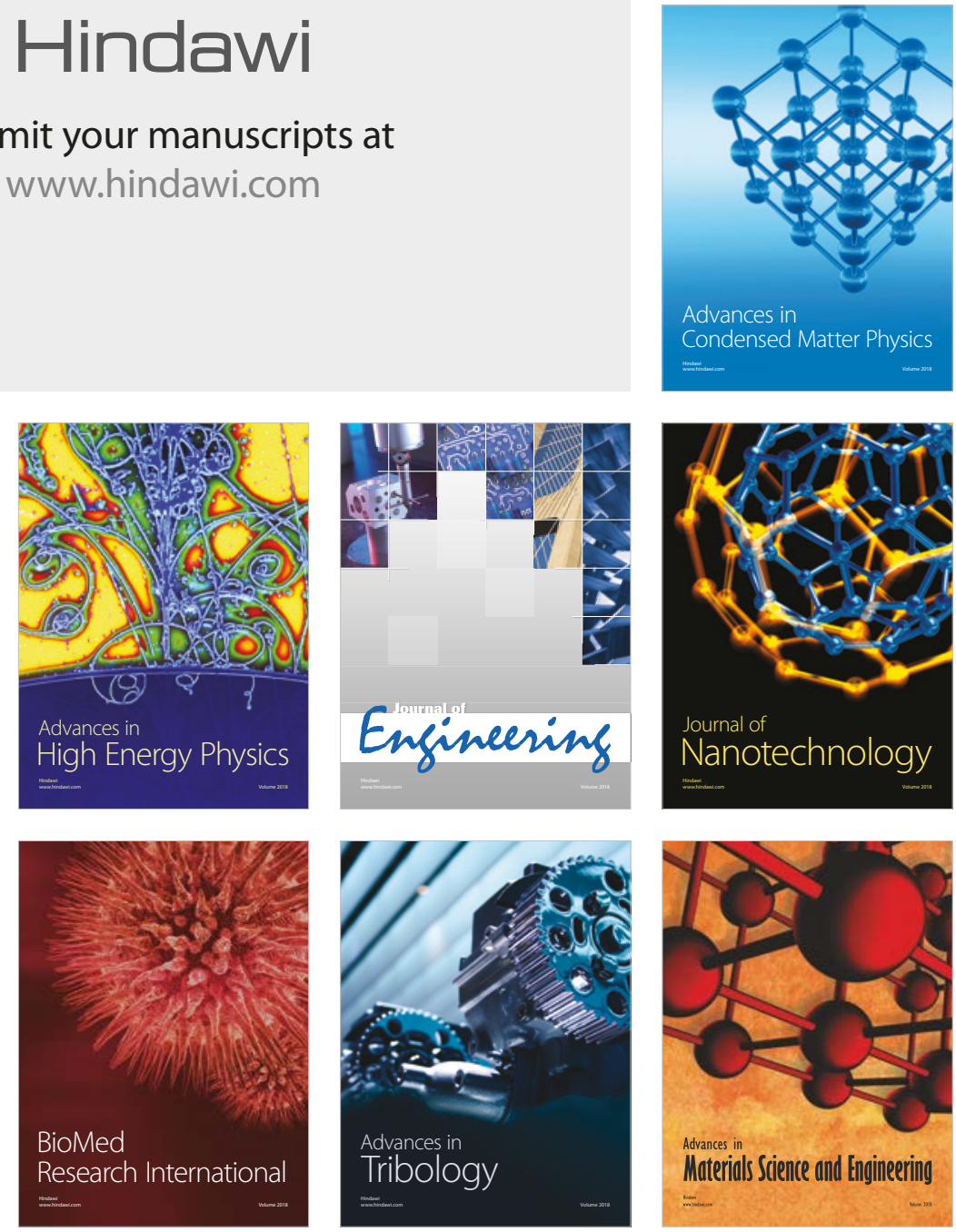